\title{
Participation and Partnership Within Revival Process. Case Study of a City of Poznan in
} Poland

\author{
Dominika Pazder PhD \\ Poznan University of Technology, Faculty of Architecture
}

\begin{abstract}
In the following paper there are presented the projects implemented by the Author, together with the Division of Revitalization of the City of Poznan. The issues were undertaken within a revitalization process - especially in its soft, social aspect. Presented effects are results of a long-term cooperation with Poznan Municipality. The main attention is focused on selected activities related to the issues of renewal and activation of public spaces and those of educational value. These are important tools to start a dialogue with city residents and can have a positive impact on social attitude to revival process.
\end{abstract}

\section{Introduction}

Process of either creation or revitalization of urban space within a city centre requires the need to ensure the increase of public participation. It is particularly important at local level. The local community should be given an opportunity to have an effect on changes in their space of living. It is essential within a renewal process to gather residents' opinions and ideas about future development so as to provide a success of taken steps. Local community must have the opportunity to present its point of view, identify its needs, preferences and aspirations. The participation process should be realized from the very beginning of revitalization program development. Thanks to the participation in the process of recovery program, the community has a chance to develop the sense of responsibility for the space, which is especially important at the stage of putting the area for use. Regeneration programs require consultation and social acceptance, though their final form is a result of decisions of the public authorities.

\section{Participation in revival process - chosen aspects}

Participation should relate primarily to those social groups that are directly involved in the planning process and will feel the consequences of certain decisions. These include residents of the district or municipality as well as various interest groups of: property or land owners, road users, elderly and disabled people, potential investors, developers, local politicians and representatives of science and culture.

The participation of these groups in the planning process should take place at the level of the creation of planning documents, which is regulated in Poland from 2015 by the revitalization law. The appropriate organization of public participation is also very important, if only because, those entities that have a high social position or capital are in a privileged position. This could has a negative effect leading to abuse and manipulation aimed at meeting the needs of only a narrow, selected group of people. It is also important to prepare the representatives of local governments to such cooperation, so as to obtain the desirable benefits. The most important is to gain general benefits for local community and not to enable political parties and particular groups of interests to realize their individual needs.

For that reason, participatory planning is the most desirable tool in a discussion about a potential of a given space and its development. The desirable instruments to start a discussion with local community are workshops, meetings, project presentations, during which local community and experts are gathered together in order to find a common vision of development or revitalization of a given area.

\section{Partnership within revival process - chosen aspects}

The validity of the issue of a city space revitalization is also strongly emphasized in educational activities, both in the departments of architecture or urban planning of Polish universities. The nature of these activities is two-dimensional: theoretical and practical, and their main aim is to develop qualified staff with different professional profiles, professionally 
dealing with urban issues. Urban planning, due to the complexity of the questions is interdisciplinary. It can be understood as art and science of building, expansion and planning of the city.

An example of partnership within a revitalization process can be a collaboration of local authorities with universities, which in Poznan already has a long tradition and brings very good results. The impact of Poznan universities for spatial planning and urban development is expressed by taking the subject of scientific research related to the specifics of settlements in a region of Wielkopolska. It can be realized by organizing scientific conferences, urban and architectural competitions. These activities result in both inventory elaboration or architectural and planning concepts which are very useful to start the discussion about future of a district, city or even municipality.

As part of the educational process carried out by the Faculty of Architecture of Poznan University of Technology, there was established the cooperation with a number of cities and municipalities in Wielkopolska region, including Municipality of the city of Poznan. It was realized generally in two basic ways:

1. joint organization and implementation of student internships (e.g. summer fieldwork), which aimed not only at an inventory of the existing urban space, but also contained specific design solutions,

2. joint organization of students' competitions, which can produce various design solutions (in different scales) concerning development of chosen areas of a city. The effects of competitions are always presented to a broad public forum, with the participation of local authorities and local community. The chosen student works are rewarded in various competitions, including prestigious ones as "My Wielkopolska Region", which are organized by the professional associations in cooperation with local authorities.

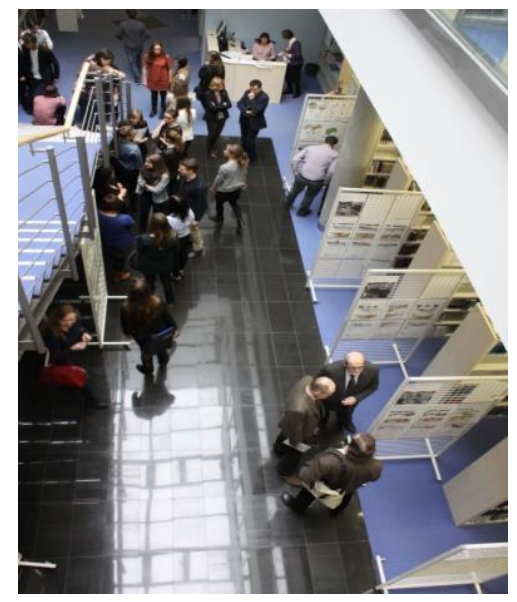

Pic.1. Presentaions, discussions and exhibitions of students' works as a tool of partnership within city revival process - ex ample of cooperation with Międzychód Municipality [photo author]. 


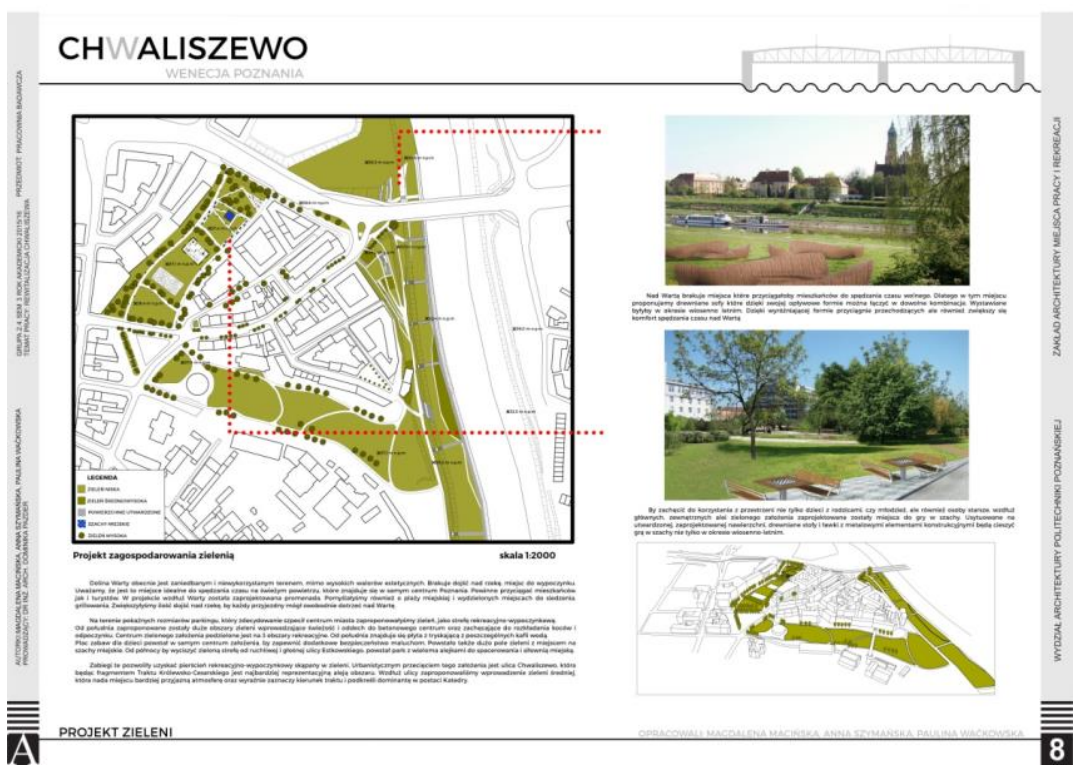

Pic.2. The example of students' work under author's direction - propos al of a public space activation within a city centre of Poznan.

The undertaken actions are aimed at promoting knowledge and real public participation in planning and revitalization process. The idea is to search for innovative solutions based on the participation of multidisciplinary teams of professionals and involvement of the local community. The result of participatory planning and collaborative revitalization is social consensus about decisions taken at each level of planning: strategic, programmatic and implementation. In this perspective, the role of architect and urban planner should be understood more broadly than just in the meaning of a city space creation. There must be also taken into account the need for new challenges in the sphere of information, education and negotiating. In this context, it is important to create new theoretical solutions including the possibility of their implementation and use in order to minimize conflicts caused by different aims and interests of various social groups.

\section{Case study - chosen activities concerning revitalization process}

An interesting example of a long-term cooperation between Poznan Municipality with universities is an initiative "Change your backyard". So far there were held seven editions until 2016 which were organized in the framework of the Municipal Revitalisation Programme. The first pilot project was completed in 2010 in the form of "Green Workshop". The idea was taken from the methodology of the game "City of the Future", which is part of the "Creative Cities" project developed by the British Council and conducted in several cities throughout the world including Oslo, Glasgow, Canberra. The game proves that a creative approach, innovation, commitment and entrepreneurship of city residents can improve the attractiveness and functional offer of individual backyards, neighborhoods and entire cities.

The aim of the "Change your backyard" was to find ideas for the development and revival of the courtyards in the downtown area of Poznan within Jeżyce district. The game was attended by representatives of different backgrounds: residents who have applied to participate in workshops, architects, urban planners, specialists in greenery, designers, representatives of various associations, NGO's and Poznan authorities.

The project was done in a form of two-day workshops and its last stage was to evaluate all developed concepts and to choose the best ones. Criteria to be considered included attractiveness, innovation, durability and performance. In addition to the greening of backyards, the result of the workshop was the creation of several murals that were attractive and in visual way revitalized selected areas. The project, funded by Poznan Municipality, was carried out by the Association No Women No Art, which invited chosen artists from the collective PartTimeHeroesCollective. All the murals were created in collaboration with residents, managers and owners of individual houses of the yard. 
In 2015, the action of "Change your backyard" covered six areas in Poznan city center, aiming at the improvement of a space in cooperation with local communities. Design workshops which are always constituted as a first phase of the project, are needed to define problems, set goals and find the best solutions. During the meetings there were presented characteristic features of given locations so to identify the key needs and set priorities, create concepts in project groups and to discuss the action plan and next steps to be taken so as to implement the best ideas. This year's seventh edition of the "Change your backyard" project concerned courtyards in the center of Poznan. The motto of the campaign was "Design, perform, use". As a result of workshops conducted with experts and local residents there had been developed new concepts of land use within the chosen backyards. The prize for the winning group was the opportunity to initiate the implementation of a Project with a slight financial suport from Poznan Municipality.

\section{Conclusions}

The cooperation of Poznan authorities with the scientific community is an interesting tool for participatory planning. The participation process realized with the support of didactic and scientific process (e.g. projects, workshops and meetings involving both experts, students and local community) contributes to an increase of the awareness of direct consumers and city space users like residents, investors, managers and designers in the field of urban development, especially concerning public space within a city centre. It is also a very important element of the renewal process integrating different methods of planning. This kind of partnership seems to be a desirable method to integrate the theoretical assumptions of urban planning with revitalization and city development practice.

\section{Bibliography}

[1] Charrette. Kształcenie urbanistów w Polsce. Rola urbanisty w programowaniu procesów rewitalizacji, Poznań 2008

[2] http://charrette.org/

[3] http://www.charretteinstitute.org/charrette.html

[4] Pazder D., Innovation and creativity in a design of high quality public space. Case study of Poznan, Poland, MCSER Publishing, Mediterranean Journal of Social Sciences, Vol.5, No.19, August 2014, Rome-Italy

[5] Pazder D., Creative functions as a tool of city space revival - case study of spa city in Wielkopolska region, New Perspectives On Economics And Business Studies, EUSER - European Center for Science Education and Research, Rome, Italy, 2015

[6] Pazder D., Creativity as a tool of a spatial activation of a city centre. Case study of polish city of Poznan, The International Journal of Social Sciences and Humanities Invention, Valley International Journals, Volume 3, issue 6, 2016

[7] Pazder D., Kaźmierczak B., Participation in public space renewal. Case study of Poznan - large city in Poland, European Journal of Social Sciences Education and Research, vol. $6 \mathrm{nr}$ 2, 2016 